\title{
LOSS OF VISION FROM CRANIAL ARTERITIS WITHOUT OTHER SYMPTOMS*
}

BY

\author{
R. W. ROSS RUSSELL AND C. J. EARL \\ The National Hospital, Queen Square, London
}

IT has been known for 20 years that cranial arteritis may be complicated by loss of vision through inflammation of the ophthalmic artery or of its branches. This event, which often results in total and permanent blindness, affects about one-third of patients with the disease and usually occurs during or shortly after the inflammation of the scalp arteries.

It has been suggested that ophthalmic arteritis may occur alone, or alternatively that inflammation in the scalp arteries may be symptomless, so that the patient may suffer loss of vision without previous headache or constitutional disturbance. Such an event has only rarely been reported (Siegert, 1952; Wagener and Hollenhorst, 1958) but is of considerable diagnostic interest. Two further cases are recorded below.

\section{Case Reports}

Case 1, an 85-year-old woman, came to St. Thomas's Hospital in September, 1958, complaining of sudden visual disturbance in the right eye which she had noticed on waking 10 days before. She described it as a grey mist over the lower half of the visual field which had remained for 3 or 4 days before spreading and becoming denser until she could discern objects only in the upper and outer quadrant of that field. Eventually after a week the eye had lost all perception of light. She had experienced no diplopia and no pain in the eye, head, or face, and had little disturbance of general health apart from anorexia and slight loss of weight. On direct questioning she denied scalp tenderness, pain on eating, and excessive sweating. The vision in the left eye, which was myopic, had been poor since childhood, but in the right eye it had previously been excellent.

Examination.-She was a pallid and delicate old woman who gave a lucid history. Her temperature was $99 \cdot 8^{\circ} \mathrm{F}$. and her pulse rate 100 per minute. The temporal and occipital arteries pulsated normally and were not tender or unduly prominent. The cardiovascular system was normal for her age and her blood pressure was $130 / 80$.

She had no perception of light in the right eye and the right fundus showed a pale disc with a few small radiating haemorrhages. The retina was also oedematous, particularly round the disc. The retinal arteries were attenuated but the veins were full and tortuous with much variation in calibre. The left fundus showed only long-standing myopic changes.

Movements of the right eye were limited upwards and medially with slight ptosis of the lid. The left eye moved fully. No other abnormality was found.

Laboratory Investigations.-Haemoglobin 84 per cent. (Haldane); white blood count 7,400/c.mm.; differential count normal; erythrocyte sedimentation rate $55 \mathrm{~mm}$./hour (Westergren). Serum proteins total $6.6 \mathrm{~g} . / 100 \mathrm{ml}$. (albumin $4.5 \mathrm{~g}$, globulin $2.1 \mathrm{~g}$.); electrophoresis normal pattern.

Diagnosis.-Cranial arteritis, confirmed by biopsy of the right superficial temporal artery. 
Treatment.-Steroids (prednisone $10 \mathrm{mg}$. three times a day) and anticoagulants (Phenindione).

Result.-There was no visual improvement but the ophthalmoplegia after fluctuating for a few days recovered completely. The temperature quickly returned to normal and the erythrocyte sedimentation rate fell to $11 \mathrm{~mm}$./hour after one week. Anticoagulants were continued for 2 weeks and steroids for a further 6 months.

Case 2, a man aged 68, noticed slight mistiness of vision in the right eye on November 25, 1960. The left eye was unaffected. Over the course of 36 hours the right eye steadily and painlessly became quite blind, and 5 days later he awoke blind in the left eye and from that time he was completely sightless. There was no complaint of headache or scalp tenderness at any time, no diplopia, and no premonitory visual symptoms. He felt perfectly well, his weight was steady, and he had experienced no fever or muscle pains apart from an episode of stiffness and discomfort in shoulders and hips, lasting some months, 3 years previously.

Examination.-When he was seen at the National Hospital 12 weeks after the onset of visual symptoms he was quite blind and both optic discs showed a moderate degree of pallor. Physiological cups were normal and the vessels showed mild thickening of the walls. Pulsation in the central retinal artery occurred with pressure on the globe and the remainder of the retina showed no abnormality. The pupils were large and regular, and did not react to light, although reacting normally to attempted convergence. External ocular movements were full and the remainder of the nervous system was intact.

In the general examination all peripheral vessels pulsated normally and both temporal arteries could be easily felt. The left temporal artery was nodular and a little larger than the right but neither was tender. The blood pressure was $135 / 80 \mathrm{~mm}$. $\mathrm{Hg}$. Temperature $98 \cdot 0^{\circ} \mathrm{F}$.

Laboratory Tests.-Haemoglobin $13.8 \mathrm{~g} . / 100 \mathrm{ml}$.; white blood count 8,300/c.mm.; differential count normal; erythrocyte sedimentation rate $34 \mathrm{~mm}$./hour (Westergren). Serum proteins total $7 \cdot 4 \mathrm{~g} . / 100 \mathrm{ml}$, with increase in the $\alpha 2$ and $\gamma$ fractions.

Cerebrospinal fluid normal. Air encephalogram to exclude a compressive lesion of the chiasm showed the ventricle to be normal in size and position. $X$ rays of the chest showed slight cardiac enlargement and unfolding of the aorta. Electrocardiograph normal.

Biopsy of the left superficial temporal artery showed chronic inflammatory changes in all coats. The elastic lamina was broken up and there were many large multinucleate giant cells. The media was fibrotic; the whole vessel wall was greatly thickened.

Diagnosis.-The appearances were typical of giant cell arteritis.

Treatment.-Prednisolone $5 \mathrm{mg}$. three times a day.

Result.-There was no return of vision.

\section{Discussion}

The visual symptoms and physical signs.in these patients are typical of those which occur in cranial arteritis. Of particular diagnostic value in Case 1 are the acute onset of visual blurring involving a segment of the field, the association with transient ophthalmoplegia, and the fundus appearance of a pale oedematous disc and retina with distended irregular veins and threadlike arteries. The symptoms and fundus appearances in Case 2 are consistent with ischaemic optic neuritis due to occlusion of the branch of the central retinal artery supplying the optic nerve rather than of the central artery itself.

It is well recognized that cranial arteritis may account for many obscure cases of visual loss, and ophthalmologists have been advised to palpate the temporal arteries and to inquire after headache and constitutional disturbance in elderly subjects 
showing any of these characteristics (Bruce, 1949). A fact which is less well known and which is emphasized here is that a patient may go blind as a result of ophthalmic arteritis with minimal clinical evidence of temporal arteritis or with no evidence at all.

Fortunately the erythrocyte sedimentation rate is invariably raised during the stage of active inflammation (Wagener and Hollenhorst, 1958), and this is an invaluable screening test which should never be omitted. In cases of doubt biopsy of a scalp vessel should be performed even if pulsation appears normal and there is no external evidence of inflammation.

\section{Summary}

Two cases of ophthalmic arteritis are described in which loss of vision occurred without clinical evidence of arterial inflammation elsewhere. The erythrocyte sedimentation rate, however, was raised and biopsy of temporal arteries showed the typical appearance of cranial arteritis.

Suggestions are made for the detection of such cases in the future.

Our thanks are due to Dr. R. E. Kelly for permission to publish the first case.

\section{REFERENCES}

Bruce, G. M. (1949). Trans. Amer. ophthal. Soc., 47, 300.

Siegert, P. (1952). Klin. Mbl. Augenheilk., 120, 254.

WAGEner, H. P., and HollenhORST, R. W. (1958). Amer. J. Ophthal., 45, 617. 